\title{
The human intestinal microbiome at extreme ages of life. Dietary intervention as a way to counteract alterations
}

\section{Nuria Salazar ${ }^{1}$, Silvia Arboleya ${ }^{2}$, Lorena Valdés ${ }^{1}$, Catherine Stanton ${ }^{2}$, Paul Ross ${ }^{3}$, Lorena Ruiz ${ }^{3}$, Miguel Gueimonde ${ }^{1}$ and Clara G. de los Reyes-Gavilán ${ }^{1 *}$}

\author{
${ }^{1}$ Department of Microbiology and Biochemistry of Dairy Products, Instituto de Productos Lácteos de Asturias - Consejo Superior de Investigaciones \\ Científicas, Villaviciosa, Spain \\ ${ }^{2}$ Alimentary Pharmabiotic Centre, Teagasc, Food Research Centre Moorepark, Fermoy, Ireland \\ ${ }^{3}$ Alimentary Pharmabiotic Centre, University College Cork, Cork, Ireland
}

\section{Edited by:}

Lynnette Robin Ferguson, The University of Auckland, New Zealand

\section{Reviewed by:}

Matthew Philip Greig Barnett, AgResearch Limited, New Zealand Dug Yeo Han, The University of Auckland, New Zealand Sharon Ross, National Cancer Institute, USA

\section{${ }^{*}$ Correspondence:}

Clara G. de los Reyes-Gavilán, Department of Microbiology and Biochemistry of Dairy Products, Instituto de Productos Lácteos de Asturias - Consejo Superior de Investigaciones Científicas,

Paseo Río Linares S/N, Villaviciosa, Asturias 33300, Spain

e-mail: greyes_gavilan@ipla.csic.es
The intestinal microbiome is defined as the assembly of genomes from microorganisms inhabiting the gut. This microbial ecosystem regulates important functions of the host and its correct composition and functionality is essential for a "healthy status." Metagenomic studies have highlighted variations of the intestinal microbiota as a function of age and diet. Colonization of the infant gut starts at birth and is influenced by feeding habits (formula vs. breast-feeding), birth mode and antibiotic exposure. The intestinal microbiota of full-term vaginally delivered breast-fed infants is considered the gold-standard, representing the reference for studies of alterations in other pediatric populations. At 2-3 years of age, the intestinal microbiota reaches a composition similar to adults, remaining without noticeable variations until senescence, when microbial instability and changes reappear. Here we summarize the current knowledge on intestinal microbiota alterations at extreme stages of life and tools for designing differentiated nutritional strategies by the use of probiotics, prebiotics and specific nutrients in order to restore a balanced microbiota and to improve immune and nutritional status.

Keywords: intestinal microbiome, elderly, newborns, dietary intervention, probiotics

\section{INTRODUCTION}

It is increasingly clear that the gut microbiota is essential for maintaining health. Until recently its role in human health had remained largely unknown, mainly due to the lack of methods to study unculturable microorganisms, which constitute a large fraction of the gut microbiota. However, in recent years the development of next generation sequencing (NGS) methods has facilitated the performance of metagenomic studies to determine gut microbiome composition. These methods, together with the use of gnotobiotic animals have demonstrated the importance of the microbiota for host health, providing the basis for the use of dietary interventions aimed at counteracting microbiota aberrancies.

Next generation sequencing have indicated that, in spite of a high inter-individual variability, human intestinal bacterial populations of adults can be classified into three robust clusters called "enterotypes," dominated by Bacteroides, Prevotella, and Ruminococcus (Arumugam et al., 2011). These enterotypes seem independent of nationality, age, gender, and body mass index but are influenced by long-term dietary habits (Wu et al., 2011). In addition, some microbiota alterations are associated with different human diseases (Turnbaugh et al., 2009; Qin et al., 2010; Karlsson etal., 2013). However, to date most of the larger studies have focused on adult populations and we are still far from clearly understanding as to how the microbiota affects health at different life stages. Interestingly, whilst the microbiota shows a high stability and resilience to change during adult life, it seems to be far more unstable at early infancy and senescence.

The initial steps of microbiota establishment in the newborn are critical for a proper development (El Aidy et al., 2013; Borre etal., 2014), and may be affected by several factors (Johnson and Versalovic, 2012). During the initial colonization the microbiota suffers microbial succession phenomena and is unstable (Yatsunenko et al., 2012). Similarly, at senescence the microbiota suffers new changes, becoming unstable again (Claesson etal., 2011, 2012; Salazar etal., 2013). Therefore, it is at these extremes of life where strategies aiming at microbiome modulation may have a deeper impact on health.

\section{CULTURE INDEPENDENT AND OMIC TECHNIOUES FOR THE STUDY OF THE INTESTINAL MICROBIOTA}

Most studies on the intestinal microbiota have focused on microbial communities and their variation among human subgroups, in order to define which microorganisms are in the gut and how their presence/absence correlates with human health. Compositional variation can be detected through polymerase chain reaction-denaturing gradient gel electrophoresis (PCR-DGGE) of $16 \mathrm{~S}$ rRNA gene, coupled to Sanger sequencing (Huipeng et al., 2014). Fluorescence in situ hybridization (FISH) and quantitative PCR (qPCR) also allow quantification 
of selected bacteria in mixed populations, but requires design of probes/primers and therefore cannot detect unknown or low abundance microbial groups. Therefore, total 16S rRNA gene sequencing through NGS platforms (454-Pyrosequencing, MiSeq, Ion Torrent, or SOLID) is becoming the gold-standard for overcoming the limitations of the aforementioned methods. NGS platforms are improving to offer cheaper alternatives and better resolution to detect unculturable, unknown and low frequent bacteria (Claesson et al., 2011; Fouhy et al., 2012; Mitra et al., 2013). Significant bioinformatic efforts are required to analyze the millions of reads generated through NGS. Alternative high-throughput methods include oligonucleotide microarrays (PhyloChip, Microbiota Array, HuGChip, and HITChip), that determine the presence and abundance of thousands of phylotypes in a sample (Paliy and Agans, 2012; Tottey et al., 2013) although de novo probe design, optimization and validation is time consuming (van den Bogert et al., 2011). Microarray and NGS showed good correlation though minor differences may appear depending, among other factors, on the origin of samples and number of $16 \mathrm{~S}$ rRNA gene copies. Both techniques can be complementary: microarray technology is a powerful method for routine study of many samples whereas NGS enables a detailed understanding of microbial gene diversity (Roh et al., 2010).

Current efforts focus on shotgun metagenomic sequencing to generate comprehensive gene catalogs reflecting what metabolic functionalities the intestinal microbiota encodes (Qin et al., 2010; Cotillard etal., 2013; Rampelli etal., 2013). Despite the large compositional variation among healthy individuals, distribution of functionality is more conserved, suggesting that microbiota metabolic potential might be more relevant than its taxonomical composition. Metagenomics also revealed activities exclusive from gut environments and provided the basis to describe new vitamins synthesis and signaling pathways (Jones et al., 2008). Moreover, shotgun sequencing coupled with in vitro enrichment cultures from fecal samples, allowed complete genomes assembly of unculturable methanogenic archaeons, demonstrating that low frequency bacteria encode functionalities that might be relevant in the cross-talk between microbiota and host (Borrel et al., 2012; Luo et al., 2012). Functional microarrays are also available such as the CAZymes Chip that detects thousands of carbohydrate degrading activities encoded by a microbiota sample (El Kaoutari et al., 2013).

What gut microbes are actually doing can be investigated through a combination of metatranscriptomics, metaproteomics, and metabolomics approaches to analyze RNA, protein and small metabolite pools from feces (Gosalbes et al., 2011; Marcobal et al., 2013; Franzosa etal., 2014; Ursell et al., 2014), which are subsequently identified by comparison against appropriate databases. Comprehension of the role that human microbiota plays in health and disease requires integration of taxonomical and metabolic features as well as the understanding of the crosstalk between microbiota and host. Metabolomics provide the basis to evaluate dietary intervention's effects on gut microbiota composition/functionality and host metabolic outcomes (Marcobal et al., 2013; Daniel et al., 2014). Development of computational tools to integrate results from multiple levels still remains a challenge.

\section{INTESTINAL MICROBIOTA, IMMUNE SYSTEM, AND NUTRITIONAL STATUS THROUGHOUT LIFE NEWBORNS}

Traditionally, it was thought that microbial colonization of the gastrointestinal tract begins immediately after birth. Recent studies have shown the presence of microorganisms in placenta, amniotic fluid, umbilical cord blood, and meconium (Jiménez et al., 2005; DiGiulio, 2012; Moles et al., 2013; Aagaard et al., 2014). The classical pattern of early microbial development involves a first colonization by facultative anaerobes, which deplete the initial oxygen supplies creating a more suitable environment for the subsequent colonization by strict anaerobes (Fanaro et al., 2003). From an initial low diversity and complexity the intestinal microbiota reaches a stable population similar to that of an adult around 2-3 years of age (Koenig et al., 2011; Yatsunenko et al., 2012). The microbial population established in the initial stages of life has a profound impact on epigenetic programming and future homeostasis and well-being of the individual (Palmer et al., 2007; Canani etal., 2011). In this way, it is known that maternal and neonatal under-nutrition may promote an inadequate gut microbiota composition and functionality, accounting for deviant programming of later immunity and of regulation of genes involved in lipid and carbohydrate metabolism (Canani et al., 2011; Kerperien et al., 2012).

Several factors influence the establishment and composition of the infant intestinal microbiota: feeding type, delivery mode, gestational age or the use of antibiotics, among others (Penders et al., 2006). Breast milk is considered the optimal feeding pattern for newborns and the WHO recommends exclusive breast-feeding up to 6 months of age and then supplemental breast-feeding up to 2 years of age (WHO, 2009). Short- and long-term health benefits associated with breast-feeding have been reported and breastfed infants are considered healthier, showing lower incidence of enteric and non-enteric infections, necrotizing enterocolitis (NEC), allergy and atopic disorders or diabetes compared with formula-fed infants (Le Huerou-Luron et al., 2010). Breast milk contains a wide range of protective compounds including carbohydrates (such as oligosaccharides with strong prebiotic activity and ability to displace pathogens), nucleotides, immunoglobulins, cytokines, short chain fatty acids (SCFA), and lactoferrin, and is a source of beneficial bacteria (Marques et al., 2010; Solís et al., 2010; Bode, 2012). The intestine of breast-fed infants was traditionally considered to be dominated by bifidobacteria but recent studies using high-throughput $16 \mathrm{~S}$ rDNA techniques demonstrated that Proteobacteria dominate the infant intestinal microbiota (Arboleya et al., 2012a; Fan et al., 2014). However, breast-fed infants presented higher levels and abundance of bifidobacteria and lower levels of potential pathogens than formula-fed babies, in which a more diverse microbiota dominated by Bacteroides and Clostridia resides, with higher levels of Klebsiella (Fallani et al., 2010; Bezirtzoglou et al., 2011). Differential patterns of SCFA production have been found in breast-fed vs. formula-fed infants (Le Huerou-Luron et al., 2010; Arboleya et al., 2012b). Weaning promoted higher levels of Bacteroidetes and Firmicutes as well as functional genes characteristic of adult microbiome whereas it decreases Bifidobacteria and Proteobacteria (Fallani et al., 2011; Koenig et al., 2011). The establishment of the so-called human 
"enterotypes" seems to start around 18 months, although at this early age these enterotypes are still susceptible to shifting (Bergstrom et al., 2014).

\section{ADULTS}

The human gut microbiota reaches its maximum complexity at adolescence following a gradual increase in the phylogenetic diversity of the microbiome during adulthood. The gut of healthy adults is populated by around $10^{14}$ bacteria which outnumber the total eukaryotic cells of the human body. This ecosystem is dominated by the phyla Bacteroidetes and Firmicutes while Actinobacteria, Proteobacteria, and Verrucomicrobia are represented in lower percentages (Arumugam et al., 2011). In addition to bacterial and eukaryotic cells, the main representative of Archaea in the adult gut is the methanogenic species Methanobrevibacter smithii (Eckburg et al., 2005).

The human microbiome contributes to shaping the immune system and should not be underestimated as a key factor in the maintenance of human health, being a key player in vitamin production, digestion, energy homeostasis, angiogenesis and maintenance of intestinal barrier integrity. The human gut microbiota appears altered in several disease states including obesity, inflammatory bowel disease and irritable bowel syndrome. The responses of the microbiota to antibiotic treatment can vary depending on individuals and is influenced by the prior exposure and the type of antibiotic used (Sullivan et al., 2001).

The "adult-like" gut microbiota ecosystem maintains a high stability and homeostasis in the absence of significant ecological stressors but intestinal dysbiosis appears with the old age.

\section{ELDERLY}

Aging has been defined as "the regression of physiological function accompanied by advancement of age" (Woodmansey, 2007) and is associated with physiological changes in the gastrointestinal tract, as well as changes in dietary patterns and immune function. Aging is intimately linked with a decline in the normal function of the immune system (Haq and McElhaney, 2014) which results in an increased vulnerability of individuals against common infections (immunosenescence). Although physiological phenomena linked to aging vary among people and is influenced by external factors, according to the WHO most westernized countries have accepted the chronological age of 65 years as a definition of "elderly." Malnutrition is a classical feature of old age and is linked to physiological changes that impact food digestion and absorption. Increased threshold for taste and smell, swallowing difficulties and masticatory dysfunction in the elderly can result in nutritionally imbalanced diets. Elderly people also suffer from atrophic gastritis with a decreased absorption of calcium, ferric iron, and vitamin B12 (Biagi et al., 2012). In addition, reduced intestinal motility leads to fecal impaction and constipation and an increased intestinal transit time is linked with reduced bacterial excretion and augmentation of bacterial protein fermentation, which consequently alters the gut fermentative process (Biagi etal., 2012).

The imbalance between pro-inflammatory and anti-inflammatory status in aged people results in a low-grade chronic systemic inflammation known as "inflammaging." Inflammaging contributes to frailty, which is considered a hallmark of unhealthy aging, and degenerative disorders (Biagi et al., 2012). The main changes in the immune system include reduced humoral responses, decreases in dendritic cells efficiency to activate $\mathrm{T}$ and $B$ cell populations, declination in the generation of new naive $\mathrm{T}$ and $\mathrm{B}$ cells, and reduced natural killer cell activity (Vallejo, 2011). Also augmented levels of pro-inflammatory cytokines such as TNF- $\alpha$, IL12 and the chemokine IL8, and a reduction in NK cells cytotoxic activity have been reported (Salazar et al., 2013). These alterations contribute to the prevalence of cancer, autoimmune and chronic diseases such as Alzheimer's disease, atherosclerosis, osteoarthritis and insulin resistance (Haq and McElhaney, 2014). The origins and drivers of the age-related chronic inflammation are not entirely clear but there is a growing body of evidence suggesting the role of the age-related intestinal microbiota in inflammaging.

The core microbiota composition of elderly individuals significantly differs from healthy adults and the set of microbial genes required for the proper maintenance of the gut homeostasis is likely to be different than that required for younger populations (Qin et al., 2010). The abundance of the members of the dominant phyla of the gut microbiota, Firmicutes and Bacteroidetes in elders is controversial and seems to be country dependent (Biagi et al., 2012). A higher proportion of Bacteroidetes and a reduced stability of the microbial community has been reported in the elderly Irish population, whereas the proportion of Bacteroidetes remains constant in Italian elderly (Biagi et al., 2013). The age-related intestinal microbiota changes include a reduction in species diversity of most bacterial groups which makes microbiota less resistant to major fluctuations in response to several environmental factors. Shifts in the dominant species within several bacterial groups, decline in beneficial microorganisms, increase of facultative anaerobic bacteria and decrease in the availability of total SCFA have also been described (Salazar et al., 2013). These modifications of the intestinal microbiota may contribute to the establishment of a state prone to disease and might increase the susceptibility to infections, such as those caused by Clostridium difficile (Biagi et al., 2012).

\section{NUTRITIONAL STRATEGIES FOR RESTORING A BALANCED MICROBIOTA AT EXTREME AGES OF LIFE}

The microbiota of specific healthy human groups is considered a reference to identify targets for intervention in order to promote a balanced microbiota in populations at extreme ages of life. The gold standard microbiota in infants is that of full-term vaginally delivered breast-fed babies. Early stages of intestinal colonization when the microbiota is still developing, is the key period to apply modulation strategies. Identified alterations of the infant microbiota generally impact on microbial diversity, anaerobe/facultative anaerobes ratio, incidence and levels of Enterobacteriaceae and intestinal pathogens, SCFA production pattern, and functionality of metagenomes (Arboleya et al., 2012a,b,d). Lowering the incidence and severity of NEC as well as the infection risk in premature infants is a target of relevance (Wang et al., 2009). The main targets for nutritional intervention in order to restore a balanced microbiota in newborns are summarized in Table $\mathbf{1}$. 


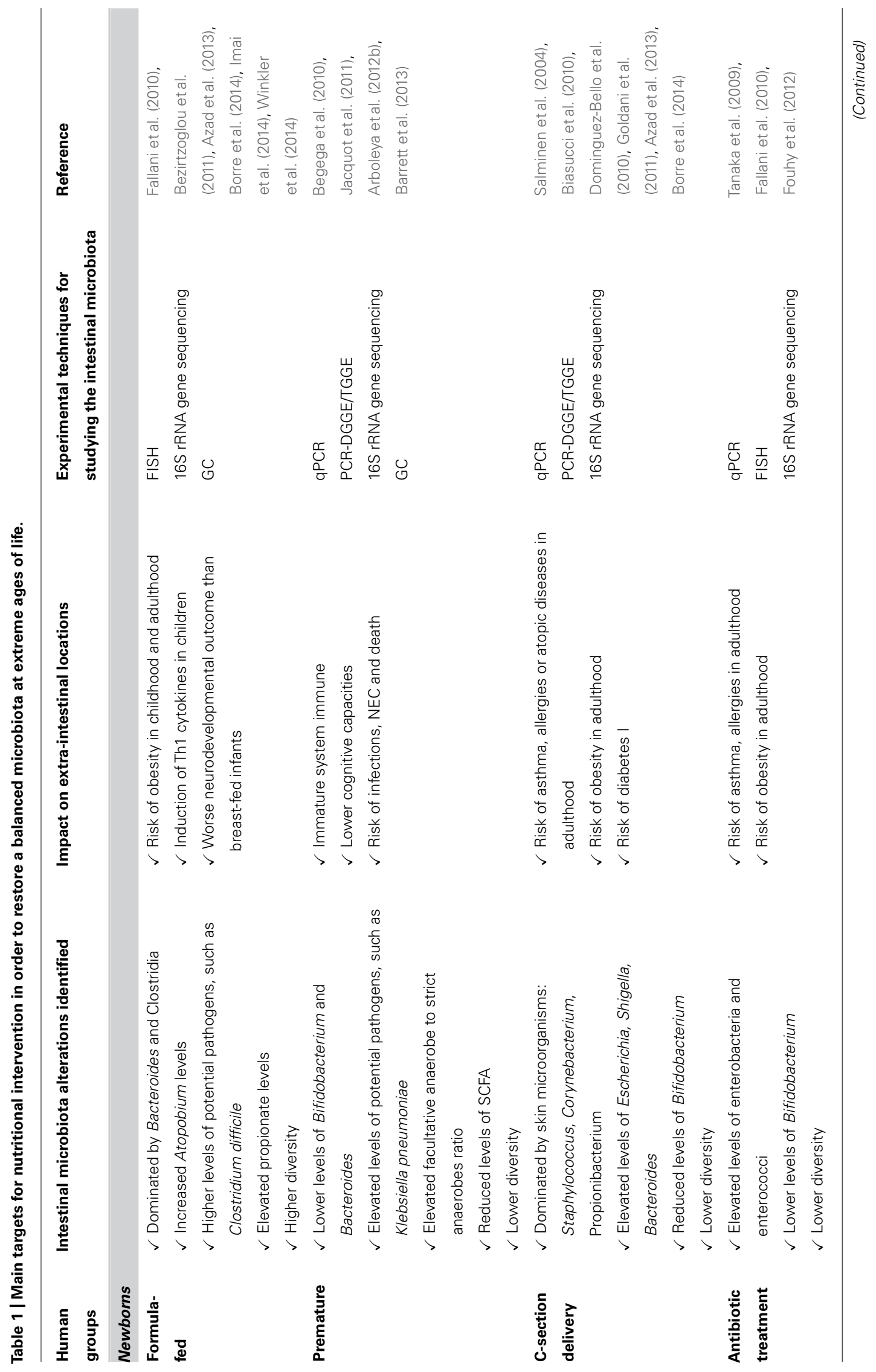




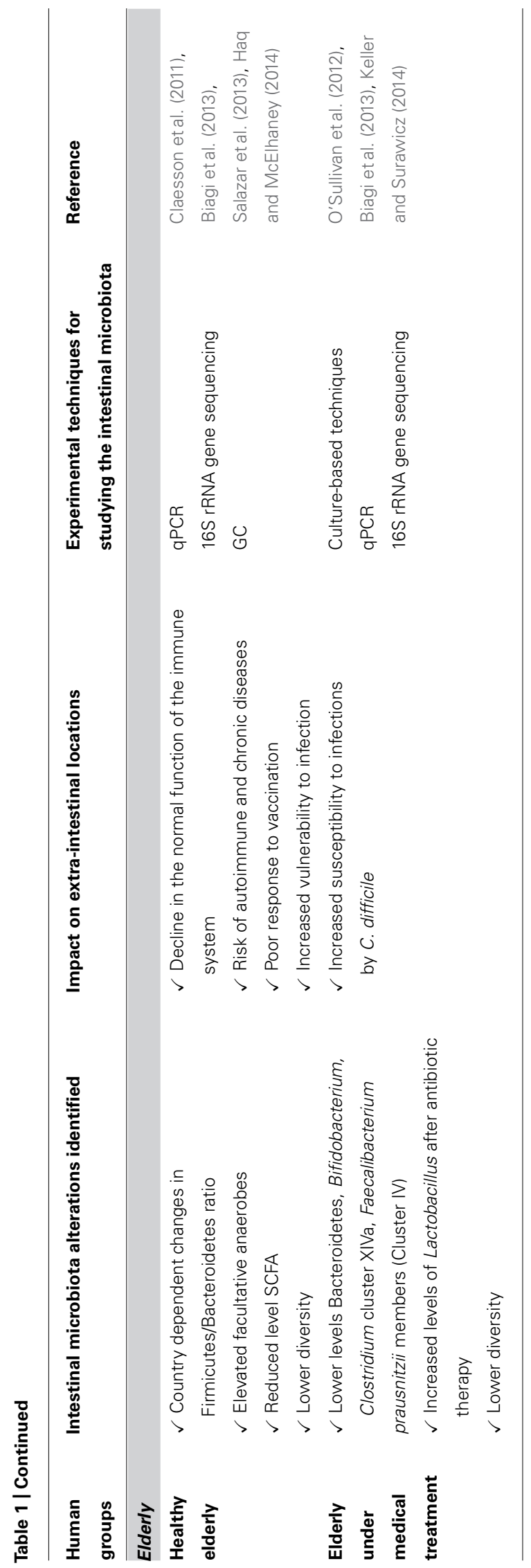

In the elderly, the microbiota of a younger population of healthy adults otherwise sharing similar characteristics in terms of geographic location and diet as the older people is considered the benchmark of healthy microbiota. This reference group must have had a past socio-economic status as similar as possible to the elders: a history of exposure to different environments in the two populations may lead to attribute to aging, variations due to the action of different environmental factors such as those linked to social habits, nutritional patterns, or residence location (Claesson et al., 2012; Salazar et al., 2013). Loss of the community-associated microbiota, that is the set of microorganisms shared by individuals from a given social group, correlated with increased frailty. The reduced levels of C. leptum and Blautia coccoides and the higher incidence of $C$. difficile infections are relevant targets (Salazar et al., 2013; Power et al., 2014). Some nutritional deficiencies of elders are related with lower intakes of specific nutrients which are important for maintaining the immune and gastrointestinal functions and which are a consequence of the general loss of functionality of the gastrointestinal tract (González et al., 2013; Power et al., 2014). Therefore, nutritional strategies in elders should consider the intestinal microbiota, immune system, and nutritional deficiencies (Table 1).

Different approaches have been proposed for restoring a balanced microbiota. Fecal transplantation is known from many years ago (Eiseman et al., 1958); although a renewed interest has arisen in recent time, this alternative has currently important ethical concerns and legal barriers (Ratner, 2014); however, it could be considered as proof of principle research that would help to find a definite cocktail of strains to be administered as a corrective measure of intestinal dysbiosis (Petrof et al., 2013).

Probiotics are "live microorganisms which when administered in adequate amount confer a health benefit on the host" (FAO/WHO, 2006). The most used probiotics in foods are lactobacilli and bifidobacteria. Probiotics may interact with the intestinal microbiota, inhibit enteric pathogens and modulate the immune system. Prebiotics are "selectively fermented ingredients that result in specific changes in the composition and/or activity of the gastrointestinal microbiota, thus conferring benefit(s) upon host health" (Roberfroid et al., 2010). Prebiotics usually are complex carbohydrates naturally present in vegetables and other foods or can be industrially produced as ingredients. Their beneficial effects are linked to promotion of changes on the composition and metabolic activity of the intestinal microbiota (Roberfroid et al., 2010). The inclusion of probiotics and prebiotics in foods has been extensively used for modulating the gut microbiota. However, to date the specific needs of defined target populations, such as the extremes of life, in terms of microbiota modulation have not been taken into account for probiotic or prebiotic selection and products formulation. A schematic representation of the steps involved in designing nutritional intervention strategies for human extreme ages is provided in Figure 1.

\section{INTEGRATED PERSPECTIVE AND FUTURE TRENDS OF THE HUMAN INTESTINAL MICROBIOTA AND DIET}

The development of dietary intervention strategies specifically targeted to populations at the extreme ages of life, may constitute an 


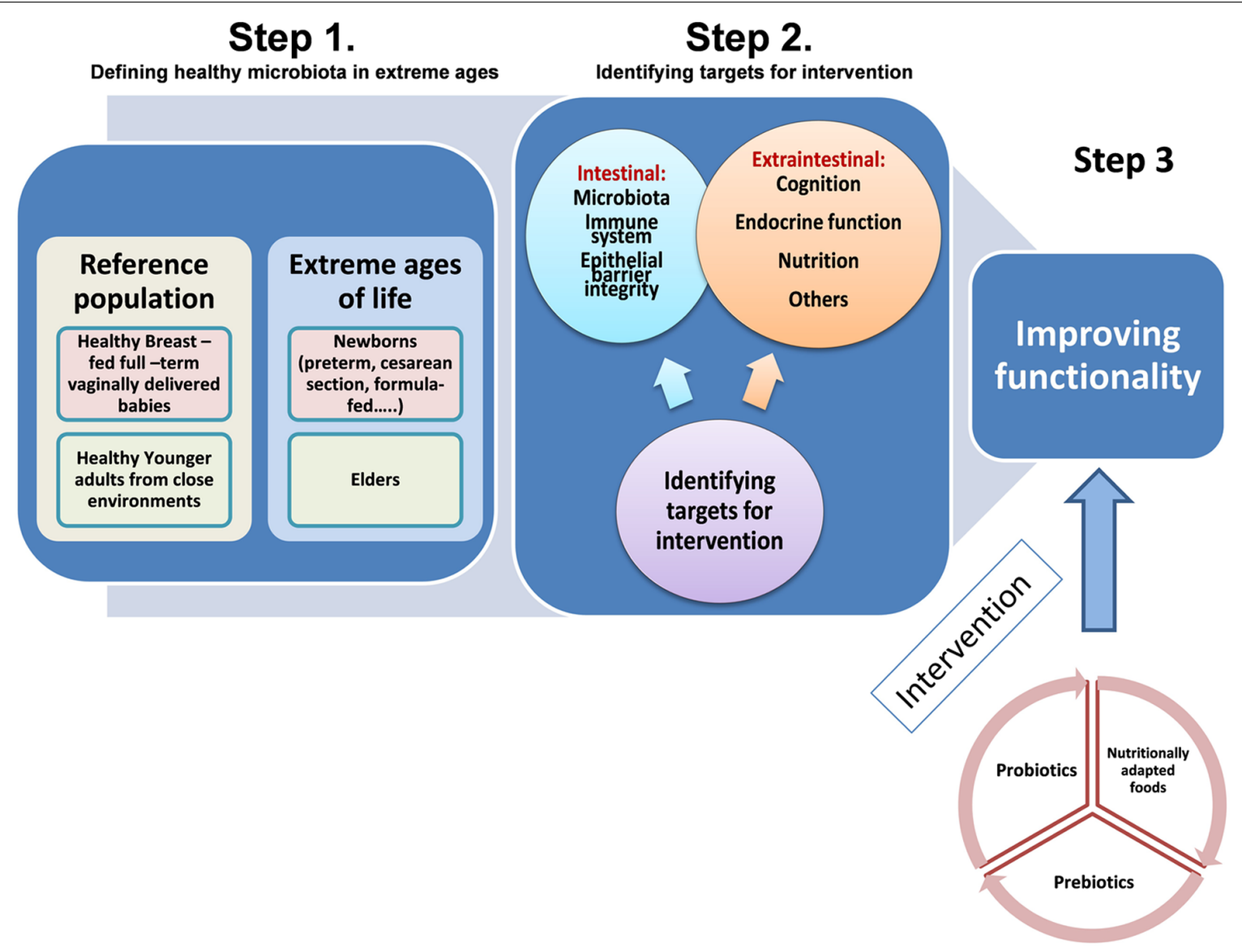

FIGURE 1 | Schematic representation of the steps involved in designing nutritional interventions to improve functionality of specific human population groups in the extreme ages of life: (newborns and elders).
Step 1: defining reference populations for comparative studies. Step 2: identifying intestinal and extraintestinal targets for intervention. Step 3: proving functional efficacy of different nutritional strategies. interesting approach (Arboleya et al., 2012c). A number of studies support the benefits of specific probiotics and prebiotics in adults (Power et al., 2014), although the evidence is still scarce in infants and elders. Several studies indicate that prebiotics may be effective in decreasing the rate of overall infections in infants (Lohner et al., 2014) and that maternal probiotic supplementation may decrease the incidence of NEC in breastfed preterm babies (Benor et al., 2014). However, there is still a need for longterm follow-up of initiated probiotic studies to assess the impact of early life interventions for late efficacy (Videhult et al., 2014). Therefore, the selection of probiotics and prebiotics included in tailor-made foods for human populations at extreme ages of life and targeting well defined microbiota alterations, is a key future action (Aggett et al., 2003; Adlerberth and Wold, 2009; Duncan and Flint, 2013). This is pointed out by recent reports underlining a high inter-individual variability in the response to probiotics (van Baarlen et al., 2011; Grzeskowiak et al., 2012) and important differences in the effect of the same probiotics and prebiotics on the intestinal microbiota from different human groups (Arboleya et al., 2013).

Moreover, considering the wide impact of the microbiota on host physiology it may be time for addressing new targets such as the age-related chronic-inflammation (Macpherson and Harris, 2004) or the maintenance or correct development of cognitive function in elders and preterm babies, respectively (Gilbert et al., 2013). In addition, these population groups may require specific and nutritionally adequate products able to satisfy their particular requirements. Such knowledge should now be integrated into the development of a new generation of highly adapted functional food products.

\section{ACKNOWLEDGMENTS}

Spanish authors acknowledge the support from the Plan Nacional and Plan Estatal de I+D (Ministry of Economy and Competitiveness) through the projects AGL2010-16525 and AGL2013-43770$\mathrm{R}$, respectively. Irish authors were funded by Science Foundation Ireland-funded Centre for Science, Engineering and Technology, the Alimentary Pharmabiotic Centre.

\section{REFERENCES}

Aagaard, K., Ma, J., Antony, K. M., Ganu, R., Petrosino, J., and Versalovic, J. (2014). The placenta harbors a unique microbiome. Sci. Transl. Med. 6:237ra265. doi: 10.1126/scitranslmed.3008599

Adlerberth, I., and Wold, A. E. (2009). Establishment of the gut microbiota in Western infants. Acta Paediatr. 98, 229-238. doi: 10.1111/j.1651-2227.2008.01060.x 
Aggett, P. J., Agostoni, C., Axelsson, I., Edwards, C. A., Goulet, O., Hernell, O., et al. (2003). Nondigestible carbohydrates in the diets of infants and young children: a commentary by the ESPGHAN Committee on Nutrition. J. Pediatr. Gastroenterol. Nutr. 36, 329-337. doi: 10.1097/00005176-200303000-00006

Arboleya, S., Ang, L., Margolles, A., Yiyuan, L., Dongya, Z., Liang, X., et al. (2012a). Deep 16S rRNA metagenomics and quantitative PCR analyses of the premature infant fecal microbiota. Anaerobe 18, 378-380. doi: 10.1016/j.anaerobe.2012.04.013

Arboleya, S., Binetti, A., Salazar, N., Fernández, N., Solís, G., HernándezBarranco, A., et al. (2012b). Establishment and development of intestinal microbiota in preterm neonates. FEMS Microbiol. Ecol. 79, 763-772. doi: 10.1111/j.1574-6941.2011.01261.x

Arboleya, S., Gonzalez, S., Salazar, N., Ruas-Madiedo, P., de los Reyes-Gavilan, C. G., and Gueimonde, M. (2012c). Development of probiotic products for nutritional requirements of specific human populations. Eng. Life Sci. 12, 368-376. doi 10.1002/elsc.201100129

Arboleya, S., Solís, G., Fernández, N., de los Reyes-Gavilán, C. G., and Gueimonde, M. (2012d). Facultative to strict anaerobes ratio in the preterm infant microbiota: a target for intervention? Gut Microbes 3, 583-588. doi 10.4161/gmic. 21942

Arboleya, S., Salazar, N., Solís, G., Fernández, N., Hernández-Barranco, A. M. Cuesta, I., et al. (2013). Assessment of intestinal microbiota modulation ability of Bifidobacterium strains in in vitro fecal batch cultures from preterm neonates. Anaerobe 19, 9-16. doi: 10.1016/j.anaerobe.2012.11.001

Arumugam, M., Raes, J., Pelletier, E., Le Paslier, D., Yamada, T., Mende, D. R., et al (2011). Enterotypes of the human gut microbiome. Nature 473, 174-180. doi: 10.1038 /nature09944

Azad, M. B., Konya, T., Maughan, H., Guttman, D. S., Field, C. J., Chari, R. S., et al (2013). Gut microbiota of healthy Canadian infants: profiles by mode of delivery and infant diet at 4 months. CMAJ 185, 385-394. doi: 10.1503/cmaj.121189

Barrett, E., Kerr, C., Murphy, K., O’Sullivan, O., Ryan, C. A., Dempsey, E. M., etal. (2013). The individual-specific and diverse nature of the preterm infant microbiota. Arch. Dis. Child. Fetal Neonatal Ed. 98, F334-F340. doi: 10.1136/archdischild-2012-303035

Begega, A., Méndez Lopez, M., De Iscar, M. J., Cuesta-Izquierdo, M., Solís G., Fernández-Colomer, B., et al. (2010). Assessment of the global intelligence and selective cognitive capacities in preterm 8-year-old children. Psicothema 22 648-653.

Benor, S., Marom, R., Ben Tov, A., Domany, K. A., Zaidenbeg-Israeli, G., and Dollberg, S. (2014). Probiotic supplementation in mothers of very low birth weight infants. Am. J. Perinatol. 31, 497-503. doi: 10.1055/s-0033-1353490

Bergstrom, A., Skov, T. H., Bahl, M. I., Roager, H. M., Christensen, L. B., Ejlerskov K. T., et al. (2014). Establishment of intestinal microbiota during early life: a longitudinal, explorative study of a large cohort of Danish infants. Appl. Environ. Microbiol. 80, 2889-2900. doi: 10.1128/AEM.00342-14

Bezirtzoglou, E., Tsiotsias, A., and Welling, G. W. (2011). Microbiota profile in feces of breast- and formula-fed newborns by using fluorescence in situ hybridization (FISH). Anaerobe 17, 478-482. doi: 10.1016/j.anaerobe.2011.03.009

Biagi, E., Candela, M., Fairweather-Tait, S., Franceschi, C., and Brigidi, P. (2012). Aging of the human metaorganism: the microbial counterpart. Age (Dordr.) 34, 247-267. doi: 10.1007/s11357-011-9217-5

Biagi, E., Candela, M., Turroni, S., Garagnani, P., Franceschi, C., and Brigidi, P. (2013). Ageing and gut microbes: perspectives for health maintenance and longevity. Pharmacol. Res. 69, 11-20. doi: 10.1016/j.phrs.2012.10.005

Biasucci, G., Rubini, M., Riboni, S., Morelli, L., Bessi, E., and Retetangos, C. (2010). Mode of delivery affects the bacterial community in the newborn gut. Early. Hum. Dev. 86(Suppl. 1), 13-15. doi: 10.1016/j.earlhumdev.2010.01.004

Bode, L. (2012). Human milk oligosaccharides: every baby needs a sugar mama. Glycobiology 22, 1147-1162. doi: 10.1093/glycob/cws074

Borre, Y. E., O’Keeffe, G. W., Clarke, G., Stanton, C., Dinan, T. G., and Cryan, J. F. (2014). Microbiota and neurodevelopmental windows: implications for brain disorders. Trends Mol. Med. 20, 509-518. doi: 10.1016/j.molmed.2014.05.002

Borrel, G., Harris, H. M., Tottey, W., Mihajlovski, A., Parisot, N., Peyretaillade, E., et al. (2012). Genome sequence of "Candidatus Methanomethylophilus alvus" Mx1201, a methanogenic archaeon from the human gut belonging to a seventh order of methanogens. J. Bacteriol. 194, 6944-6945. doi: 10.1128/JB. 01867-12
Canani, R. B., Di Costanzo, M., Leone, L., Bedogni, G., Brambilla, P., Cianfarani, S., et al. (2011). Epigenetic mechanisms elicited by nutrition in early life. Nutr. Res. Rev. 24, 198-205. doi: 10.1017/s0954422411000102

Claesson, M. J., Cusack, S., O’Sullivan, O., Greene-Diniz, R., De Weerd, H., Flannery, E., et al. (2011). Composition, variability, and temporal stability of the intestinal microbiota of the elderly. Proc. Natl. Acad. Sci. U.S.A. 108(Suppl. 1), 4586-4591. doi: 10.1073/pnas.1000097107

Claesson, M. J., Jeffery, I. B., Conde, S., Power, S. E., O’Connor, E. M., Cusack, S., et al. (2012). Gut microbiota composition correlates with diet and health in the elderly. Nature 488, 178-184. doi: 10.1038/nature11319

Cotillard, A., Kennedy, S. P., Kong, L. C., Prifti, E., Pons, N., Le Chatelier, E., et al. (2013). Dietary intervention impact on gut microbial gene richness. Nature 500, 585-588. doi: 10.1038/nature12480

Daniel, H., Moghaddas Gholami, A., Berry, D., Desmarchelier, C., Hahne, H., Loh, G., et al. (2014). High-fat diet alters gut microbiota physiology in mice. ISME J. 8, 295-308. doi: 10.1038/ismej.2013.155

DiGiulio, D. B. (2012). Diversity of microbes in amniotic fluid. Semin. Fetal Neonatal Med. 17, 2-11. doi: 10.1016/j.siny.2011.10.001

Dominguez-Bello, M. G., Costello, E. K., Contreras, M., Magris, M., Hidalgo, G., Fierer, N., et al. (2010). Delivery mode shapes the acquisition and structure of the initial microbiota across multiple body habitats in newborns. Proc. Natl. Acad. Sci. U.S.A. 107, 11971-11975. doi: 10.1073/pnas.1002601107

Duncan, S. H., and Flint, H. J. (2013). Probiotics and prebiotics and health in ageing populations. Maturitas 75, 44-50. doi: 10.1016/j.maturitas.2013. 02.004

Eckburg, P. B., Bik, E. M., Bernstein, C. N., Purdom, E., Dethlefsen, L., Sargent, M., et al. (2005). Diversity of the human intestinal microbial flora. Science 308, 1635-1638. doi: 10.1126/science.1110591

Eiseman, B., Silen, W., Bascom, G. S., and Kauvar, A. J. (1958). Fecal enema as an adjunct in the treatment of pseudomembranous enterocolitis. Surgery 44, 854-859.

El Aidy, S., Hooiveld, G., Tremaroli, V., Bäckhed, F., and Kleerebezem, M. (2013). The gut microbiota and mucosal homeostasis: colonized at birth or at adulthood, does it matter? Gut Microbes 4, 118-124. doi: 10.4161/gmic.23362

El Kaoutari, A., Armougom, F., Leroy, Q., Vialettes, B., Million, M., Raoult, D., et al. (2013). Development and validation of a microarray for the investigation of the CAZymes encoded by the human gut microbiome. PLoS ONE 8:e84033. doi: 10.1371/journal.pone.0084033

Fallani, M., Amarri, S., Uusijarvi, A., Adam, R., Khanna, S., Aguilera, M., etal. (2011). Determinants of the human infant intestinal microbiota after the introduction of first complementary foods in infant samples from five European centres. Microbiology 157, 1385-1392. doi: 10.1099/mic.0. 042143-0

Fallani, M., Young, D., Scott, J., Norin, E., Amarri, S., Adam, R., et al. (2010). Intestinal microbiota of 6-week-old infants across Europe: geographic influence beyond delivery mode, breast-feeding, and antibiotics. J. Pediatr. Gastroenterol. Nutr. 51, 77-84. doi: 10.1097/MPG.0b013e3181d1b11e

Fan, W., Huo, G., Li, X., Yang, L., and Duan, C. (2014). Impact of diet in shaping gut microbiota revealed by a comparative study in infants during the six months of life. J. Microbiol. Biotechnol. 24, 133-143. doi: 10.4014/jmb.1309.09029

Fanaro, S., Chierici, R., Guerrini, P., and Vigi, V. (2003). Intestinal microflora in early infancy: composition and development. Acta Paediatr. Suppl. 91, 48-55.

FAO/WHO. (2006). Probiotics in Food: Health and Nutritional Properties and Guidelines for Evaluation. FAO Food and Nutrition Paper 85. Food and Agriculture Organization of the United Nations and World Health Organization, Rome. Available at: ftp://ftp.fao.org/docrep/fao/009/a0512e/a0512e00.pdf [accessed April 3, 2008].

Fouhy, F., Ross, R. P., Fitzgerald, G. F., Stanton, C., and Cotter, P. D. (2012). Composition of the early intestinal microbiota: knowledge, knowledge gaps and the use of high-throughput sequencing to address these gaps. Gut Microbes 3, 203-220. doi: $10.4161 /$ gmic.20169

Franzosa, E. A., Morgan, X. C., Segata, N., Waldron, L., Reyes, J., Earl, A. M., et al. (2014). Relating the metatranscriptome and metagenome of the human gut. Proc. Natl. Acad. Sci. U.S.A. 111, E2329-E2338. doi: 10.1073/pnas.1319284111

Gilbert, K., Gire, R., and Rousseau, G. (2013). Probiotics and Gut-Brain Axis: promising area in well-being. Agro Food Ind. Hi Tech 24, 6-9.

Goldani, H. A., Bettiol, H., Barbieri, M. A., Silva, A. A., Agranonik, M., Morais, M. B., et al. (2011). Cesarean delivery is associated with an increased risk of 
obesity in adulthood in a Brazilian birth cohort study. Am. J. Clin. Nutr. 93, 1344-1347. doi: 10.3945/ajcn.110.010033

González, S., López, P., Margolles, A., Suárez, A., Patterson, A. M., Cuervo, A., et al. (2013). Fatty acids intake and immune parameters in the elderly. Nutr. Hosp. 28, 474-478. doi: 10.3305/nh.2013.28.2.6183

Gosalbes, M. J., Durbán, A., Pignatelli, M., Abellan, J. J., Jiménez-Hernández, N., Pérez-Cobas, A. E., etal. (2011). Metatranscriptomic approach to analyze the functional human gut microbiota. PLOS ONE 6:e17447. doi: 10.1371/journal.pone.0017447

Grzeskowiak, L., Gronlund, M. M., Beckmann, C., Salminen, S., Von Berg, A., and Isolauri, E. (2012). The impact of perinatal probiotic intervention on gut microbiota: double-blind placebo-controlled trials in Finland and Germany. Anaerobe 18, 7-13. doi: 10.1016/j.anaerobe.2011.09.006

Haq, K., and McElhaney, J. E. (2014). Immunosenescence: influenza vaccination and the elderly. Curr. Opin. Immunol. 29C, 38-42. doi: 10.1016/j.coi.2014.03.008

Huipeng, W., Lifeng, G., Chuang, G., Jiaying, Z., and Yuankun, C. (2014). The differences in colonic mucosal microbiota between normal individual and colon cancer patients by polymerase chain reaction-denaturing gradient gel electrophoresis. J. Clin. Gastroenterol. 48, 138-144. doi: 10.1097/MCG.0b013e3182a26719

Imai, C. M., Gunnarsdottir, I., Thorisdottir, B., Halldorsson, T. I., and Thorsdottir, I. (2014). Associations between infant feeding practice prior to six months and body mass index at six years of age. Nutrients 6, 1608-1617. doi: 10.3390/nu6041608

Jacquot, A., Neveu, D., Aujoulat, F., Mercier, G., Marchandin, H., JumasBilak, E., etal. (2011). Dynamics and clinical evolution of bacterial gut microflora in extremely premature patients. J. Pediatr. 158, 390-396. doi 10.1016/j.jpeds.2010.09.007

Jiménez, E., Fernández, L., Marín, M. L., Martín, R., Odriozola, J. M., Nueno-Palop C., et al. (2005). Isolation of commensal bacteria from umbilical cord blood of healthy neonates born by cesarean section. Curr. Microbiol. 51, 270-274. doi: 10.1007/s00284-005-0020-3

Johnson, C. L., and Versalovic, J. (2012). The human microbiome and its potential importance to pediatrics. Pediatrics 129, 950-960. doi: 10.1542/peds.2011-2736

Jones, B. V., Begley, M., Hill, C., Gahan, C. G., and Marchesi, J. R. (2008). Functional and comparative metagenomic analysis of bile salt hydrolase activity in the human gut microbiome. Proc. Natl. Acad. Sci. U.S.A. 105, 13580-13585. doi: 10.1073/pnas.0804437105

Karlsson, F. H., Tremaroli, V., Nookaew, I., Bergstrom, G., Behre, C. J., Fagerberg, B., et al. (2013). Gut metagenome in European women with normal, impaired and diabetic glucose control. Nature 498, 99-103. doi: 10.1038/ nature 12198

Keller, J. M., and Surawicz, C. M. (2014). Clostridium difficile infection in the elderly. Clin. Geriatr. Med. 30, 79-93. doi: 10.1016/j.cger.2013.10.008

Kerperien, J., Schouten, B., Boehm, G., Willemsen, L. E. M., Garssen, J., Knippels, L. M. J., et al. (2012). "Development of the immune system-early nutrition and consequences for later life," in Recent Advances in Immunology to Target Cancer, Inflammation and Infections, ed. J. Kanwar (Rijeka: InTech Europe Press), 315334.

Koenig, J. E., Spor, A., Scalfone, N., Fricker, A. D., Stombaugh, J., Knight, R., et al. (2011). Succession of microbial consortia in the developing infant gut microbiome. Proc. Natl. Acad. Sci. U.S.A. 108(Suppl. 1), 4578-4585. doi: 10.1073/pnas. 1000081107

Le Huerou-Luron, I., Blat, S., and Boudry, G. (2010). Breast- v. formula-feeding: impacts on the digestive tract and immediate and long-term health effects. Nutr Res. Rev. 23, 23-36. doi: 10.1017/S0954422410000065

Lohner, S., Kullenberg, D., Antes, G., Decsi, T., and Meerpohl, J. J. (2014). Prebiotics in healthy infants and children for prevention of acute infectious diseases: a systematic review and meta-analysis. Nutr. Rev. 72, 523-531. doi: $10.1111 /$ nure. 12117

Luo, C., Tsementzi, D., Kyrpides, N. C., and Konstantinidis, K. T. (2012). Individual genome assembly from complex community short-read metagenomic datasets. ISME J 6, 898-901. doi: 10.1038/ismej.2011.147

Macpherson, A. J., and Harris, N. L. (2004). Interactions between commensal intestinal bacteria and the immune system. Nat. Rev. Immunol. 4, 478-485. doi: $10.1038 /$ nri1373

Marcobal, A., Kashyap, P. C., Nelson, T. A., Aronov, P. A., Donia, M. S., Spormann, A., et al. (2013). A metabolomic view of how the human gut microbiota impacts the host metabolome using humanized and gnotobiotic mice. ISME J. 7, 1933-1943. doi: 10.1038/ismej.2013.89
Marques, T. M., Wall, R., Ross, R. P., Fitzgerald, G. F., Ryan, C. A., and Stanton, C. (2010). Programming infant gut microbiota: influence of dietary and environmental factors. Curr. Opin. Biotechnol. 21, 149-156. doi: 10.1016/j.copbio.2010.03.020

Mitra, S., Forster-Fromme, K., Damms-Machado, A., Scheurenbrand, T., Biskup, S., Huson, D. H., et al. (2013). Analysis of the intestinal microbiota using SOLiD 16S rRNA gene sequencing and SOLiD shotgun sequencing. BMC Genomics 14(Suppl. 5):S16. doi: 10.1186/1471-2164-14-S5-S16

Moles, L., Gomez, M., Heilig, H., Bustos, G., Fuentes, S., De Vos, W., et al. (2013). Bacterial diversity in meconium of preterm neonates and evolution of their fecal microbiota during the first month of life. PLoS ONE 8:e66986. doi: 10.1371/journal.pone.0066986

O’Sullivan, O., Coakley, M., Lakshminarayanan, B., Conde, S., Claesson, M. J., Cusack, S., et al. (2012). Alterations in intestinal microbiota of elderly Irish subjects post-antibiotic therapy. J. Antimicrob. Chemother. 68, 214-221. doi: $10.1093 / \mathrm{jac} / \mathrm{dks} 348$

Paliy, O., and Agans, R. (2012). Application of phylogenetic microarrays to interrogation of human microbiota. FEMS Microbiol. Ecol. 79, 2-11. doi: 10.1111/j.1574-6941.2011.01222.x

Palmer, C., Bik, E. M., Digiulio, D. B., Relman, D. A., and Brown, P. O. (2007). Development of the human infant intestinal microbiota. PLoS Biol. 5:e177. doi: 10.1371/journal.pbio.0050177

Penders, J., Thijs, C., Vink, C., Stelma, F. F., Snijders, B., Kummeling, I., et al. (2006). Factors influencing the composition of the intestinal microbiota in early infancy. Pediatrics 118, 511-521. doi: 10.1542/peds.2005-2824

Petrof, E. O., Gloor, G. B., Vanner, S. J., Weese, S. J., Carter, D., Daigneault, M. C., et al. (2013). Stool substitute transplant therapy for the eradication of Clostridium difficile infection: 'RePOOPulating' the gut. Microbiome 1:3. doi: 10.1186/20492618-1-3

Power, S. E., O’Toole, P. W., Stanton, C., Ross, R. P., and Fitzgerald, G. F. (2014). Intestinal microbiota, diet and health. Br. J. Nutr. 111, 387-402. doi: 10.1017/S0007114513002560

Qin, J., Li, R., Raes, J., Arumugam, M., Burgdorf, K. S., Manichanh, C., et al. (2010). A human gut microbial gene catalogue established by metagenomic sequencing. Nature 464, 59-65. doi: 10.1038/nature08821

Rampelli, S., Candela, M., Turroni, S., Biagi, E., Collino, S., Franceschi, C., et al. (2013). Functional metagenomic profiling of intestinal microbiome in extreme ageing. Aging (Albany N. Y.) 5, 902-912.

Ratner, M. (2014). Fecal transplantation poses dilemma for FDA. Nat. Biotechnol. 32, 401-402. doi: 10.1038/nbt0514-401

Roberfroid, M., Gibson, G. R., Hoyles, L., Mccartney, A. L., Rastall, R., Rowland, I., et al. (2010). Prebiotic effects: metabolic and health benefits. Br. J. Nutr. 104(Suppl. 2), S1-S63. doi: 10.1017/S0007114510003363

Roh, S. W., Abell, G. C. J., Kim, K.-H., Nam, Y.-D., and Bae, J.-W. (2010). Comparing microarrays and next-generation sequencing technologies for microbial ecology research. Trends Biotechnol. 28, 291-299. doi: 10.1016/j.tibtech.2010.03.001

Salazar, N., López, P., Valdés, L., Margolles, A., Suarez, A., Patterson, A. M., et al. (2013). Microbial targets for the development of functional foods accordingly with nutritional and immune parameters altered in the elderly. J. Am. Coll. Nutr. 32, 399-406. doi: 10.1080/07315724.2013.827047

Salminen, S., Gibson, G. R., Mccartney, A. L., and Isolauri, E. (2004). Influence of mode of delivery on gut microbiota composition in seven year old children. Gut 53, 1388-1389. doi: 10.1136/gut.2004.041640

Solís, G., de los Reyes-Gavilán, C. G., Fernández, N., Margolles, A., and Gueimonde, M. (2010). Establishment and development of lactic acid bacteria and bifidobacteria microbiota in breast-milk and the infant gut. Anaerobe 16, 307-310. doi: 10.1016/j.anaerobe.2010.02.004

Sullivan, A., Edlund, C., and Nord, C. E. (2001). Effect of antimicrobial agents on the ecological balance of human microflora. Lancet Infect. Dis. 1, 101-114. doi: 10.1016/S1473-3099(01)00066-4

Tanaka, S., Kobayashi, T., Songjinda, P., Tateyama, A., Tsubouchi, M., Kiyohara, C., et al. (2009). Influence of antibiotic exposure in the early postnatal period on the development of intestinal microbiota. FEMS Immunol. Med. Microbiol. 56, 80-87. doi: 10.1111/j.1574-695X.2009.00553.x

Tottey, W., Denonfoux, J., Jaziri, F., Parisot, N., Missaoui, M., Hill, D., et al. (2013). The human gut chip "HuGChip," an explorative phylogenetic microarray for determining gut microbiome diversity at family level. PLoS ONE 8:e62544. doi: 10.1371/journal.pone.0062544 
Turnbaugh, P. J., Hamady, M., Yatsunenko, T., Cantarel, B. L., Duncan, A., Ley, R. E., et al. (2009). A core gut microbiome in obese and lean twins. Nature 457, 480-484. doi: 10.1038/nature07540

Ursell, L. K., Haiser, H. J., Van Treuren, W., Garg, N., Reddivari, L., Vanamala, J., et al. (2014). The intestinal metabolome: an intersection between microbiota and host. Gastroenterology 146, 1470-1476. doi: 10.1053/j.gastro.2014.03.001

Vallejo, A. N. (2011). Immunological hurdles of ageing: indispensable research of the human model. Ageing Res. Rev. 10, 315-318. doi: 10.1016/j.arr.2011.01.005

van Baarlen, P., Troost, F., Van Der Meer, C., Hooiveld, G., Boekschoten, M., Brummer, R. J., et al. (2011). Human mucosal in vivo transcriptome responses to three lactobacilli indicate how probiotics may modulate human cellular pathways. Proc. Natl. Acad. Sci. U.S.A. 108(Suppl. 1), 4562-4569. doi: 10.1073/pnas.1000079107

van den Bogert, B., De Vos, W. M., Zoetendal, E. G., and Kleerebezem, M. (2011). Microarray analysis and barcoded pyrosequencing provide consistent microbial profiles depending on the source of human intestinal samples. Appl. Environ. Microbiol. 77, 2071-2080. doi: 10.1128/AEM.02477-10

Videhult, F. K., Ohlund, I., Stenlund, H., Hernell, O., and West, C. E. (2014) Probiotics during weaning: a follow-up study on effects on body composition and metabolic markers at school age. Eur. J. Nutr. doi: 10.1007/s00394-014-0715-y [Epub ahead of print].

Wang, Y., Hoenig, J. D., Malin, K. J., Qamar, S., Petrof, E. O., Sun, J., et al. (2009). 16S rRNA gene-based analysis of fecal microbiota from preterm infants with and without necrotizing enterocolitis. ISME J. 3, 944-954. doi: 10.1038/ismej.2009.37

WHO. (2009). Infant and Young Child Feeding: Model Chapter for Textbooks for Medical Students and allied Health Professionals. Geneva: WHO Press.

Winkler, B., Aulenbach, J., Meyer, T., Wiegering, A., Eyrich, M., Schlegel, P. G., et al. (2014). Formula-feeding is associated with shift towards Thl cytokines. Eur. J. Nutr. doi: 10.1007/s00394-014-0693-0 [Epub ahead of print].
Woodmansey, E. J. (2007). Intestinal bacteria and ageing. J. Appl. Microbiol. 102, 1178-1186. doi: 10.1111/j.1365-2672.2007.03400.x

Wu, G. D., Chen, J., Hoffmann, C., Bittinger, K., Chen, Y. Y., Keilbaugh, S. A., et al. (2011). Linking long-term dietary patterns with gut microbial enterotypes. Science 334, 105-108. doi: 10.1126/science.1208344

Yatsunenko, T., Rey, F. E., Manary, M. J., Trehan, I., Dominguez-Bello, M. G., Contreras, M., etal. (2012). Human gut microbiome viewed across age and geography. Nature 486, 222-227. doi: 10.1038/nature 11053

Conflict of Interest Statement: The authors declare that the research was conducted in the absence of any commercial or financial relationships that could be construed as a potential conflict of interest.

Received: 10 July 2014; accepted: 02 November 2014; published online: 21 November 2014.

Citation: Salazar N, Arboleya S, Valdés L, Stanton C, Ross P, Ruiz L, Gueimonde M and de los Reyes-Gavilán CG (2014) The human intestinal microbiome at extreme ages of life. Dietary intervention as a way to counteract alterations. Front. Genet. 5:406. doi: 10.3389/fgene.2014.00406

This article was submitted to Nutrigenomics, a section of the journal Frontiers in Genetics.

Copyright (c) 2014 Salazar, Arboleya, Valdés, Stanton, Ross, Ruiz, Gueimonde and de los Reyes-Gavilan. This is an open-access article distributed under the terms of the Creative Commons Attribution License (CC BY). The use, distribution or reproduction in other forums is permitted, provided the original author(s) or licensor are credited and that the original publication in this journal is cited, in accordance with accepted academic practice. No use, distribution or reproduction is permitted which does not comply with these terms. 